\title{
The Influence of Virtual Communities in Marketing Decision
}

\author{
Giuseppe Granata ${ }^{1} \&$ Giancarlo Scozzese ${ }^{2}$ \\ ${ }^{1}$ Departement of Economics and Law, University of Cassino and Southern Lazio, Cassino, Italy \\ ${ }^{2}$ Department of Human and Social Sciences, University for Foreigners, Perugia, Italy \\ Correspondence: Giuseppe Granata, Department of Economics and Law, University of Cassino and Southern \\ Lazio, Cassino (FR), Italy.
}

Received: September 19, 2017

doi:10.5539/ibr.v10n12p191
Accepted: November 9, 2017 Online Published: November 16, 2017

URL: https://doi.org/10.5539/ibr.v10n12p191

\begin{abstract}
Purpose - The introduction and growth of the Internet and modern technology has had a strong impact on the structures of companies and led to a change in the decisional processes. In the new economic scenarios, with the growth of social networks and Web 3.0, technologies go through de velopments and transformations that are of vital importance to ensure the competitiveness of companies.
\end{abstract}

Methodology - The study analyzes the possibility of applying social networks to the new business models, underlining their importance not only with regard to managers but also, and especially, to crowdsourcing processes.

Implications - The objective of the study is to focus on the impact that web 3.0 and social networks have on management and marketing decisions, underlining certain processes in order to improve the competitive advantages of companies.

Keywords: communication technologies, competitive strategies, crowdsourcing and social network

\section{Introduction}

The advances in corporate communication, multimedia technologies, Internet, websites, etc., are guiding a fast innovation in various sectors, pushing a new business-based business style (Garrigos, 2010), where it is important to set up business networks and other subjects becomes crucial. The new networks and the introduction of the Web 3.0 technology can change not only corporate structures but also and especially value chains and networks, with the consequent change in the decisional processes of managers.

The paper examines how social networks are important about business models, what are the effects on the Web. Finally, how these new technologies influence management and marketing decisions, what are the benefits for companies. In particular, it focuses on the importance of the community manager and on the importance of the crowdsourcing process to cope with the new changes.

\section{Literature review}

\subsection{Social Networks and Virtual Communities}

The new tools of social networks and virtual communities are fundamental to modern societies due to the combined effect they have on the behavior of organizations. Although in different contexts, social networks can assume different meanings, we want to define them like Boyd \& Ellison (2007) did, as Web-based services allowing users to:

1) build a public or semipublic profile within a limited system;

2) organize a list of other users with whom they share a connection;

3) see the lists of their own connections and other people's connections within the system.

A virtual community is defined as a "group of people who can or cannot meet face-to-face and who share words and ideas through the mediation of the Web"(Rheingold, 1993).

The potential of the Web, constantly enhanced and updated, "drives all the society and companies to work faster, and create and manage more interdependences in order to operate in global markets" (Kalpic \& Bernus 2006, page 41). All of these new trends facilitate the creation of virtual communities and promote business 
competitiveness, acting in all business areas (Garrigos et al., 2011). In particular recent years, the growth of virtual communities such as Facebook, Twitter or Youtube has been remarkable and it has had a very strong and more and more widespread impact not only on a social level but also influencing the management and marketing decisions (Granata, 2016).

They have also led to an increase in the innovation in all stages of the value chain, facilitating management activities and decisional processes in all types of organizations.

Surely social networks have proven to be essential for the creation and sharing of knowledge, and for learning as well. As Lin \& Hsueh (2006) underline, in the age of the Internet, in order to shorten the learning cycle, people can take advantage of other people's experiences to expand their own experiences, which can be achieved through sharing on the Internet.

However, their function goes beyond the management of the knowledge of organizations, since they are capable of allowing significant changes in the value chain and in the structures of all types of companies. Today, making use of the concepts related to the value chain of Porter in order to try to understand the elements of distinction and strength (value creation) of the companies operating in a given market/sector, very often turns out to be an outdated evaluation system. Ever more often it becomes necessary to talk of value network rather than value chain, since, almost always, "value is co-created by a combination of players in a network" (Pepparde \& Rylander, 2006, p. 131).

In an ever more Internet-based society and with the advent of the powerful Web and of the more user-friendly applications (Moor \& Weigand, 2007), the new communication platforms are capable of creating multiple and different channels. They can also improve the channels among customers and this will affect the various decisions on the manager side.

In this way, the recent innovations cause a change in the organization of work and processes, both inside and outside the companies, heavily affecting competitiveness and so transforming the technologies concerning production, promotion and sale of products, and improving customer retention as well. In this scope, the knowledge about how new technologies and key elements of change can be used is fundamental. Therefore, it is crucial that companies cope with these new management forms and adopt them, also transforming, when necessary, their structures in accordance with the new inno vations (Teo \& Piang, 2004; Wirtz et al, 2010), if they want to take advantage of the new opportunities that the market will offer to them, and obtain an effective and efficient organization of the management. In order to better understand the development of these new technological platforms, it is therefore of crucial importance to get into the functioning of the so-called Web 3.0.

\subsection{The Use of the Web 3.0 to Create a Virtual Community}

Over the last years, the technologic advances of the different types of the Web from 1.0 to 2.0, the emergence of the new technologies of the semantic Web and, mainly, the development of social networks, have created new forms of competition among companies, leading to a new way of managing the Web: the 3.0. With Web 3.0 we can mean "the new technologies of the Semantic Web integrated with applications on a large scale" (Hendler, 2009, page 111), digitally developed on the Web and supporting smart technologies (Fuchs et al., 2010). This new system of the Web is capable, through the manipulation of web services (reading-writing-execution), of helping companies to quickly react to changes, through the integration of data and applications coming from various different resources, providing "the capability of identifying relations through the data in different applications or in different parts of the same application"(Hendler, 2009, p. 112).

The Web 3.0 revolution is not only in the use of semantics, but also in the use of images, sound, space and feelings, affirming a concept in which the traditional Web becomes a very interactive tool. In this new scenario, intelligent tools and machines can do many things, such as reading, correlating, manipulating data in cyberspace, adapting to different companies and users according to their needs.

Thanks to the new technologies that allow listening, understanding, sharing between businesses and between customers or between any other subject that can be treated differently, based on preferences. .

With the new technologies, in the age of the Web 3.0, companies can use the information collected before, during or after their contact with the customers, through the most innovative techniques such as data warehousing, data mining or customer relationship management, and also using various information coming from social networks or from the Web in general. These information are now essential for adapting to the personalization of products, brands and services from and to different users or companies according to their needs (doing what the user wants you to do and behaving like the user wants you to behave). In summary you get a radical transformation that involves changing technologies resulting once again, a complex and evolving business models revolution. 
(Rohrbeck 2010; Garrigos et al., 2011). The creation and dissemination of networks, the technological development, the development of Web 3.0 can only be the case if the involvement and participation of people who interact, share, learn, and create content on social networks is there.

In this context, the source of competitive advantage is through personal relationships with the environment, interactions with other people sharing the same areas.

So social networks are very important and crucial to the development and improvement of marketing, and to improving the company's strategic management. They are of fundamental importance to promoting cooperation with Espert, customers and suppliers and to acquire all the necessary information by drawing on social networks. The most important change that the web deals with is the change of ambience and the subjects that exchange information. Finally, they are needed to acquire different information from the world of the network, what consortia are exchanging, what competitors are doing, what are the bad guys and what not. The latter are also of vital importance, having influence and participating in debates for the creation and promotion of the corporate image. The administration of social networks for managing the knowledge is proven to be essential, as networks are capable of promoting creativity, sharing and learning, are able to innovate and create creativity, because different stakeholders add value to the process of managing them. Then it becomes necessary to transform the customer from active to active to participate in all production processes through social networks. This method is costing companies to change their approach to the market by creating an interactive connection. One example of a company that has implemented this kind of transformation as a starting point for these transformations, we could use the information system which enabled the success of companies such as the Spanish Desigual, with its own fast-fashion retail sale network it collects information regarding products from the customers that buy from it every day. The company is able to design and manufacture, offering new products, displaying them in its own shops all over the world within a time frame of just 15 days, then it stores the specific data and the last trends of customer preferences (Ferdows et al, 2004;. Sull \& Turconi, 2008).

For example, Desigual is capable of adapting to the fast evolution of markets and estimate the sales of a given product in a given shop during a period of elaborations of the estimates of the demand. Another example is Carrefour's policy (Yoon \& Zhou, 2011), which allows customers to manage their loyalty cards (see spend, store history, check accumulated earnings, create shopping lists, share with friends, or others, etc.). It also allows sharing and interaction between customers and companies. This information from the network can be used by businesses to get feedback on products, to understand customer needs, and to prepare new products.

These examples make us understand that the evolution of the web is based on promoting sharing and participation in business development through all business partners: employees, customers, partners and all stakeholders. Throughout the social networks play an essential role in getting everyone involved in the interesting business, improving the company's reputation, marketing reputation, and enhancing inno vations that enable the creation of new business management models, valorization of already existing. It is therefore fundamental to concentrate on specific strategies in networks that could improve the participation and collaboration of the employees, of the customers and of the other interested parties, by using appropriate instruments such as the community manager and the adoption of crowdsourcing techniques.

This perspective is fundamental as it can enable the efficient outsourcing of various processes, allowing companies to become more competitive since they can free resources and human capital and focus on customers and their needs. In the new framework, in order to strengthen and consolidate these goals, we can underline the importance of participating in two of the main innovations for companies:

1) improve customer trust and corporate reputation and image through an appropriate use of social networks and figures like the "Community Manager";

2) enhance the participation of the Internet users through website personalization and through the promotion of the community manager and crowdsourcing, which will be examined below.

\section{The Manager of Virtual Communities}

The specific task of the community manager, concerning the creation, management and enhancement of the participation and collaboration in virtual communities and social networks, is of vital importance for the companies. We call community managers those managers of virtual communities who operate through multiple types of social networks and communities and are responsible for the daily functioning of said communities (Arnone et al., 2009), operating as a connection between companies and online communities, and ensuring a good relationship between them. (Michlmayr, 2009). In general, the most well-known tasks are creating, maintaining, facilitating, making dynamic, enhancing and generally ensuring and improving the dialogue and relationship of a company with customers and with the other interested subjects in the Web. However, their 
function goes further and includes important management and marketing aspects, pursuing three goals.

Firstly, they have to improve the commercialization, organization, promotion of products and events and improve the reputation of the company. In this sense, they have to improve the encounter, the participation and the collaboration of a series of interested subjects related to the online communities that are oriented also to the requirements and opinions of customers and of the other interested parties, trying to monitor and control the activity, in particular the word of mouth.

Second, they communicate the conditions of the community also taking on a management function, building metrics and analyzing the data and the key factors for success in order to help companies plan their strategies.

Finally, the community leader must promote the goal of improving some crowding processes at various points in the value chain, promoting the participation and collaboration of the involved people as described below. In this area companies, even if they focus on the use of social networks, they are not yet satisfied with the objectives achieved (Chui et al., 2009).

Most innovative businesses entrust community managers to increase performance and visibility. Almost everyone has entered the main social networks, some of which have created a social network like Ford, Pepsi, Adidas, Nike. The key element to keep in mind is that companies need to be aware of the importance of the community maneger. This manager, in addition to improving marketing activities, also improves the company's management.

\section{Discussion}

The participation system involving the various stakeholders for the enterprise within the business process is fully realized through the "crowdsourcing" that is, in the era of Web 3.0, one of the best models of business development. Crowdsourcing, also known as "massive outsourcing" or "voluntary outsourcing", is conceived in this study as the entrustment of a task or a work to a large group of people or to a community (crowd or mass) via Internet, through an open invitation. The expression was coined by Jeff Howe in the issue of June 2006 of the computer magazine Wired, and it has also been defined as "the outsourcing of tasks to the broad Internet audience in general" (Kleemann et al., 2008, p. 5). It describes a new Web-based business model that exploits the creative solutions of a distributed network of people through what is equal to an open invitation to present proposals (Brabham, 2008, p. 75), with the purpose of "animating people to give a free contribution to the production process of the company" (Kleemann et al., 2008). This has been mainly de veloped through the expansion of social networks, which has enabled the work for public outsourcing (Corney et al., 2009), with various types of remunerative processes and motivations for the participants.

Brabham (2008, page 79) underlines that the public can contribute to designing products, it produces advertisings and memorable images, it outperforms the fastest and most affordable companies and even the best minds in these scopes. Geiger et al. (2011) analyses 46

crowdsourcing examples, with 19 different types of processes. By de veloping its use, Kleemann et al. (2008, pp. 12-14) have described and shown examples of the main types of crowdsourcing: the participation of consumers in the development and configuration of the product; design of the product; competitive offers regarding tasks or specifically-defined problems; permanently open invitations; a community for reporting; evaluation of the product from the consumer side, and consumer profiles. However, the process could be much broader and might include everything, from the designing of a product or a process up to the resolution of problems of technical or other nature, from the creation of R\&D contents to advertising, and up to quality control.

\section{Conclusions}

This document has tried to analyze the influence of the so-called Web 3.0 and the development of social networks with regard to marketing and management and, more specifically, with regard to the decisional processes of companies. The study examines the former literature that concentrates on the development of social networks and virtual communities. The paper describes also the transformation of technologies and the new business of the models emerging in the new framework of the Web 3.0, and its influence on company competitiveness.

The paper also highlighted the importance of scheduled use of networks and the management of participation and sharing of the web. The study concludes by highlighting how participation, reputation, cooperation and image are important elements for managing community managers in order to improve and enhance the competitiveness of businesses. With regard to the community manager, the document analyses their functions, summarizing their role with three main points:

\section{improvement in marketing and promotion;}


$\checkmark \quad$ increase in company reputation;

$\checkmark$ improvement in company management through the realization of metrics for the communities and networks, interpreting the key factors for success in order to help companies to plan products and process strategies;

Lastly, the promotion of the participation of the parties interested in collaborating, in order to improve the crowdsourcing processes in various points of the value chain and of the value networks. The study also underlines the importance of crowdsourcing and how it can be used by companies.

Surely the paper appears to be the first step to study how new technologies impact on business and more specifically on the marketing and management decisions. We recognize that there are several limitations to the search conscious that the exploratory analysis and it will require and the fact more in-depth analysis. One example, future research should focus on the aspects and the impact that a virtual community can have on businesses and specific functions, such as sales, marketing, etc.

\section{References}

Arnone, L., Geerts, A., \& Scoubeau, C. (2009). Implementing company-managed virtual communities as a relationship marketing tool: a decision systems analysis. Journal of Customer Behaviour, 8(1), 5-27. https://doi.org/10.1362/147539209X414362

Boyd, D. M., \& Ellison, N. N. (2007). Social network sites: definition, history, and scholarship. Journal of Computer-Mediated Communication, 13(1), 210-230. https://doi.org/10.1111/j.1083-6101.2007.00393.x

Brabham, D. C. (2008). Crowdsourcing as a model for problem solving. an introduction and cases. Convergence: The International Journal of Research into New Media Technologies, 14(1), 75-90. https://doi.org/10.1177/1354856507084420

Chui, M., Miller, A., \& Roberts, R. P. (2009). Six ways to make Web 2.0 work. McKinsey on Business Technology, 16, Summer, 2-10.

Corney, J. R., Torres-Sanchez, C., Jagadeesan, A. P., \& Regli, W. C. (2009). Outsourcing labour to the cloud. International Journal of Innovation and Sustainable Development, 4(4), 294-313. https://doi.org/10.1504/IJISD.2009.033083

Ferdows, K., Lewis, M. A., \& Machuca, J. A. D. (2004). Rapid-fire fulfillment. Harvard Business Review, 82(11), 104-110.

Fuchs, C., Hofkirchner, W., Schafranek, M., Raffl, C., Sandoval, M., \& Bichler, R. (2010). Theoretical foundations of the web: cognition, communication, and co-operation. Towards an understanding of Web 1.0, 2.0, 3.0. Future Internet, 2(1), 41-59. https://doi.org/10.3390/fi2010041

Garrigos, F. (2010). Interrelationships between professional virtual communities and social networks, and the importance of virtual communities in creating and sharing knowledge. in Dasgupta, S. (Ed.), Social Computing: Concepts, Methodologies, Tools, and Applications, Vol. III, Chapter 6.6, Information Science Publishing, New York, NY, 1674-1696. https://doi.org/10.4018/978-1-60566-984-7.ch108

Garrigos, F., Gil, I., \& Narangajavana, Y. (2011). The impact of social networks in the competitiveness of the firms. in Beckford, A.M. and Larsen, J.P. (Eds), Competitiveness: Psychology, Production, Impact and Global Trends, Nova Science Publishers, Hauppauge, NY.

Geiger, D., Rosemann, M., \& Fielt, E. (2011). Crowdsourcing Information Systems - A Systems Theory Perspective. Sydney, s.n.

Granata, G. (2016). Business Communication 2.0, Aracne editor, Roma.

Hendler, J. (2009). Web 3.0 emerging. Computer, 42(1), 111-113. https://doi.org/10.1109/MC.2009.30

Kalpic, B., \& Bernus, P. (2006). Business process modeling through the knowledge management perspective. Journal of Knowledge Management, 10(3), 40-56. https://doi.org/10.1108/13673270610670849

Kleemann, F., Voß, G. G., \& Rieder, K. (2008). Un(der)paid innovators: the commercial utilization of consumer work through crowdsourcing. Science, Technology \& Innovation Studies, 4(1), July, 5-26.

Lin, F., \& Hsueh, C. (2006). Knowledge map creation and maintenance for virtual communities of practice. Information Processing and Management, 42(2), 551-568. https://doi.org/10.1016/j.ipm.2005.03.026

Michlmayr, M. (2009). Community management in open source projects. Upgrade, 10(2), 22-26. 
Moor, A., \& Weigand, H. (2007). Formalizing the evolution of virtual communities. Information Systems, 32(2), 223-247. https://doi.org/10.1016/j.is.2005.09.002

Peppard, J., \& Rylander, A. (2006). From value chain to value network: insights for mobile operators. European Management Journal, 24(2-3), 128-141. https://doi.org/10.1016/j.emj.2006.03.003

Rheingold, H. (1993). The Virtual Community, Addison-Wesley, Reading, MA.

Rohrbeck, R. (2010). Harnessing a network of experts for competitive advantage: technology scouting in the ICT industry. $R$ and D Management, 20(2). https://doi.org/10.1111/j.1467-9310.2010.00601.x

Sull, D., \& Turconi, S. (2008). Fast fashion lessons. Business Strategy Review, 19(2), 4-11. https://doi.org/10.1111/j.1467-8616.2008.00527.x

Teo, T. H. S., \& Piang, Y. (2004). A model for web adoption. Information and Management, 41(4). https://doi.org/10.1016/S0378-7206(03)00084-3

Wirtz, B. W., Schilke, O., \& Ullrich, S. (2010). Strategic development of business models: implications of the Web 2.0 for creating value on the internet. Long Range Planning, 43(2), 272-290. https://doi.org/10.1016/j.lrp.2010.01.005

Yoon, E. J., \& Zhou, W. (2011). Mixed strategy multiple-channel retailing with RFID information. Journal of Organizational Computing and Electronic Commerce, 21(4), 368-383. https://doi.org/10.1080/10919392.2011.614557

Note: To conform with Italian regulations on academic publishing, even though the article is the joint work of all the authors we attribute the contribution of each author as follows: Giuseppe Granata, sections: 1.1 and 2; Giancarlo Scozzese, sections: 1.2 and 3; Giuseppe Granata and Giancarlo Scozzese sections: 4.

\section{Copyrights}

Copyright for this article is retained by the author(s), with first publication rights granted to the journal.

This is an open-access article distributed under the terms and conditions of the Creative Commons Attribution license (http://creativecommons.org/licenses/by/4.0/). 